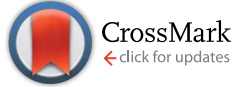

Cite this: J. Mater. Chem. A, 2015, 3, 22347

Received 13th July 2015

Accepted 1st October 2015

DOI: $10.1039 / \mathrm{c} 5 \operatorname{ta} 05280 \mathrm{~g}$

www.rsc.org/MaterialsA

\title{
High proton conductivity in cyanide-bridged metal-organic frameworks: understanding the role of water
}

\author{
Yuan Gao, Richard Broersen, Wouter Hageman, Ning Yan, Marjo C. Mittelmeijer- \\ Hazeleger, Gadi Rothenberg and Stefania Tanase*
}

\begin{abstract}
We investigate and discuss the proton conductivity properties of the cyanide-bridged metal-organic framework (MOF) $\left[\mathrm{Nd}(\mathrm{mpca})_{2} \mathrm{Nd}\left(\mathrm{H}_{2} \mathrm{O}\right)_{6} \mathrm{Mo}(\mathrm{CN})_{8}\right] \cdot n \mathrm{H}_{2} \mathrm{O}$ (where mpca is 5 -methyl-2-pyrazinecarboxylate). This MOF is one of an exciting class of cyanide-bridged materials that can combine porosity with magnetism, luminescence, and proton conductivity. Specifically, we show that this material features highly hydrophilic open channels filled with water molecules. They enable a high proton conductivity, as much as $10^{-3} \mathrm{~S} \mathrm{~cm}^{-1}$. A rich hydrogen-bonding network, formed by the ligands' carboxylate groups with both coordinated and lattice water molecules, facilitates this high proton conductivity. Combined thermogravimetric studies, FTIR spectroscopy and PXRD analysis show that upon heating at $80^{\circ} \mathrm{C}$, the lattice water molecules are removed without any change in the framework. Further heating at $130{ }^{\circ} \mathrm{C}$ results in a partial removal of the coordinated water molecules, while still retaining the original framework. These activated MOFs shows an increasing conductivity from $\sim 10^{-9} \mathrm{~S} \mathrm{~cm}^{-1}$ to $\sim 10^{-3} \mathrm{~S}$ $\mathrm{cm}^{-1}$ when the relative humidity increases from $0 \%$ to $98 \%$. Our studies show that the increase in proton conductivity is correlated with the re-hydration of the framework with lattice water molecules. The Arrhenius activation energy for the proton conductivity process is low $\left(E_{\mathrm{a}}=37 \mathrm{~kJ} \mathrm{~mol}^{-1}\right)$, indicating that the protons "hop" through the channels following the Grotthuss mechanism. The fact that this MOF is remarkably stable both under high humidity conditions and at relatively high temperatures (up to $130^{\circ} \mathrm{C}$ ) makes it a good candidate for real-life applications.
\end{abstract}

\section{Introduction}

Meeting the energy challenges that our society faces in the 21st century requires innovative materials, be it for biomass conversion, ${ }^{1} \mathrm{CO}_{2}$ abatement, ${ }^{2}$ or fuel production. ${ }^{3}$ But perhaps the most crucial of all is finding practical solutions for efficient energy conversion. Proton-exchange membrane fuel cells (PEMFCs) are one promising technology, as they have a much higher theoretical efficiency compared with internal combustion engines ( $82 \%$ vs. $35 \%$, respectively). ${ }^{4}$ Their key functional component is the ion-exchange membrane which enables the migration of protons towards the electrodes. State-of-the-art cells use Nafion-type membranes. These, however, have two thorny limitations: first, they are prone to dehydration, losing their proton conductivity above $80{ }^{\circ} \mathrm{C} .{ }^{5}$ Second, they are expensive, preventing large-scale commercial applications. ${ }^{6,7}$ It

Van 't Hoff Institute for Molecular Sciences, University of Amsterdam, Science Park 904, 1098XH Amsterdam, The Netherlands. E-mail: s.grecea@uva.nl

$\dagger$ Electronic supplementary information (ESI) available: IR, PXRD, TGA and proton conductivity analysis for the as-synthesized NdMo-MOF and its activated forms at $80{ }^{\circ} \mathrm{C}, 130{ }^{\circ} \mathrm{C}$ and $150{ }^{\circ} \mathrm{C}$, respectively. See DOI: $10.1039 / \mathrm{c} 5 \mathrm{ta} 05280 \mathrm{~g}$ is thus no surprise that designing efficient proton-conducting materials is a 'hot topic' in materials science. ${ }^{8-19}$

One possible alternative to Nafion membranes is using specially designed metal-organic frameworks (MOFs). These hybrid coordination polymers have remarkable features, including regular voids, tunable pore sizes and adjustable pore surface properties, all of which provide opportunities for controlling proton conduction paths..$^{20-25}$ The proton conductivity of MOFs arises from guest molecules (acids, water molecules or clusters) $)^{26,27}$ counterions (e.g. ammonium or imidazolium cations), $)^{12,28}$ or acidic groups on the organic linkers $\left(-\mathrm{SO}_{3} \mathrm{H}\right.$, $\left.-\mathrm{PO}_{3} \mathrm{H}\right) \cdot{ }^{29-33}$ Generally, low-temperature proton-conducting materials rely on the presence of water molecules, as their hydrogen bonding network plays a key role in the proton migration process. ${ }^{34,35}$ Thus, to design MOFs as effective proton conductors for practical applications, we must first understand the mechanisms of proton conductivity and the role of water.

MOFs containing open channels which accommodate water molecules are preferable as proton-conducting materials. In these MOFs, the favorable path for proton transfer is the hydrogen-bonded network formed by the lattice water, the coordinated water and the oxygen atoms of the organic linkers. ${ }^{36-39}$ Good stability in water is paramount for such 
proton-conducting materials, because they usually operate in a humid environment. The framework must retain numerous water molecules, and these must be mobile. This is because proton conductivity is predominantly determined by proton mobility and concentration. Designing such water-stable MOFs with appropriate frameworks and pathways for high proton conductivity is a challenge.

Lanthanide-based cyanide-bridged MOFs are a relatively new class of materials that can combine porosity with magnetism, luminescence and proton conductivity. ${ }^{40}$ Our group has developed a facile synthesis to make such MOFs by self-assembling $\left[\mathrm{M}(\mathrm{CN})_{8}\right]^{4-}(\mathrm{M}=\mathrm{Mo}, \mathrm{W})$ building-blocks with trivalent lanthanide cations in the presence of 5-methyl-2-pyrazinecarboxylic acid (Hmpca). ${ }^{\mathbf{4 1 , 4 2}}$ These MOFs have a 3D robust network with open hydrophilic channels. In addition to the luminescent and magnetic properties reported previously, ${ }^{\mathbf{4 1 , 4 2}}$ we also discovered that these MOFs exhibit excellent proton conductivity. Specifically, the NdMo-MOF, $\left[\mathrm{Nd}(\mathrm{mpca})_{2} \mathrm{Nd}\left(\mathrm{H}_{2} \mathrm{O}\right)_{6} \mathrm{Mo}(\mathrm{CN})_{8}\right] \cdot n \mathrm{H}_{2} \mathrm{O}$, (mpca $=5$-methyl-2-pyrazinecarboxylate), is one of the best proton conducting MOFs reported so far. The fact that this MOF is also stable up to $150{ }^{\circ} \mathrm{C}$ and stable in water makes it a good candidate for real-life applications. Here we report the results for proton conductivity tests using this MOF, and explain the different roles played by the water molecules based on characterisation and mechanistic studies.

\section{Experimental}

\section{Materials and instrumentation}

Infrared spectra (4000-400 $\mathrm{cm}^{-1}$, resol. $0.5 \mathrm{~cm}^{-1}$ ) were recorded on a Varian 660 FTIR spectrometer using $\mathrm{KBr}$ pellets and the transmission technique. Powder X-ray diffraction was carried out on a Rigaku Miniflex X-ray Diffractometer. Measurements were done from $3^{\circ}$ to $90^{\circ}$ with a turning speed of $2.5^{\circ} \mathrm{min}^{-1}$. Thermogravimetric analysis (TGA) and differential scanning calorimetry (DSC) were performed using a NETZSCH Jupiter ${ }^{\circledR}$ STA 449F3 instrument. The measurements were done under argon $\left(20 \mathrm{ml} \mathrm{min}^{-1}\right)$ at $35-800{ }^{\circ} \mathrm{C}$. Water and methanol sorption experiments were performed in an isothermal Setaram Calvert 80 micro-calorimeter, connected to a home-built manometric apparatus. ${ }^{43}$ Blank experiments were carried out at $30{ }^{\circ} \mathrm{C}$ by introducing a known amount of gas into the empty sample holder and measuring the final pressure. To calculate the amount adsorbed, the blank curves were subtracted, after a correction for the volume of the MOF sample itself. The phase purity of the bulk sample was confirmed by comparing the powder X-ray diffraction (PXRD) pattern of the as synthesised MOF with the simulated pattern from single-crystal XRD analysis. Unless stated otherwise, all chemicals were commercially available (Aldrich, $>99 \%$ pure) and used as received. The $\mathrm{K}_{4}\left[\mathrm{Mo}(\mathrm{CN})_{8}\right] \cdot 2 \mathrm{H}_{2} \mathrm{O}$ precursor and the NdMo-MOF were synthesized according to previously published procedures. ${ }^{42}$

\section{Procedure for measuring proton conductivity}

Samples were prepared for impedance analysis by grinding the crystalline product with a mortar and pestle to uniform particle size. The disk-shaped pellets of the NdMo-MOF were prepared by using a press and a die measuring $13 \mathrm{~mm}$ in diameter. The pellet was placed between a pair of parallel copper plates anchored by a clamp. The typical thickness of the sample was $\sim 0.4 \mathrm{~mm}( \pm 0.05 \mathrm{~mm})$. The electrochemical cell was then fixed with clamp and placed in a humidity-controlled environment which is controlled by different saturated salt solutions. Impedance analysis was measured using 4-points method at different temperatures $\left(30-90{ }^{\circ} \mathrm{C}\right)$ and relative humidities (2098\%). Electrochemical impedance spectroscopy (EIS) tests were carried out under open-circuit voltage (OCV) condition using a Gamry potentiostat (Reference 600) with a frequency range of $10^{6} \mathrm{~Hz}$ to $0.1 \mathrm{~Hz}$ and a voltage amplitude of $10 \mathrm{mV}$. The DC electrical conductivity has been calculated by measuring voltage and current at $21^{\circ} \mathrm{C}$ and $26 \% \mathrm{RH}$.

\section{Results and discussion}

X-ray single-crystal analysis of the NdMo-based MOF $\left[\mathrm{Nd}(\mathrm{mpca})_{2} \mathrm{Nd}\left(\mathrm{H}_{2} \mathrm{O}\right)_{6} \mathrm{Mo}(\mathrm{CN})_{8}\right] \cdot n \mathrm{H}_{2} \mathrm{O}$ shows that this is a hybrid inorganic-organic network with a neutral three-dimensional structure that is extended through cyanido and carboxylato bridges. ${ }^{41,42}$ Each $\left[\mathrm{Mo}(\mathrm{CN})_{8}\right]^{4-}$ centre is connected to three $\left[\mathrm{Nd}(\mathrm{mpca})_{2}\left(\mathrm{H}_{2} \mathrm{O}\right)_{2}\right.$ units via three cyanido bridges, forming a two-dimensional network of alternating diamond-like $\mathrm{Nd}_{2}$ $\mathrm{Mo}_{2}(\mathrm{CN})_{4}$ rings and octagonal $\mathrm{Nd}_{4} \mathrm{Mo}_{4}(\mathrm{CN})_{8}$ rings. These $2 \mathrm{D}$ nets are connected by $\left[\mathrm{Nd}\left(\mathrm{H}_{2} \mathrm{O}\right)_{6}\right]^{3+}$ moieties via the carboxylate group of one mpca ligand, giving an overall 3D structure (see Fig. 1). Single-crystal X-ray diffraction also shows that the hydrophilic channels accommodate both water and methanol molecules. This creates an extended hydrogen-bonded network which stabilises the 3D framework. However, when exposed to ambient conditions, the methanol is easily replaced by water without disrupting the framework. ${ }^{42}$

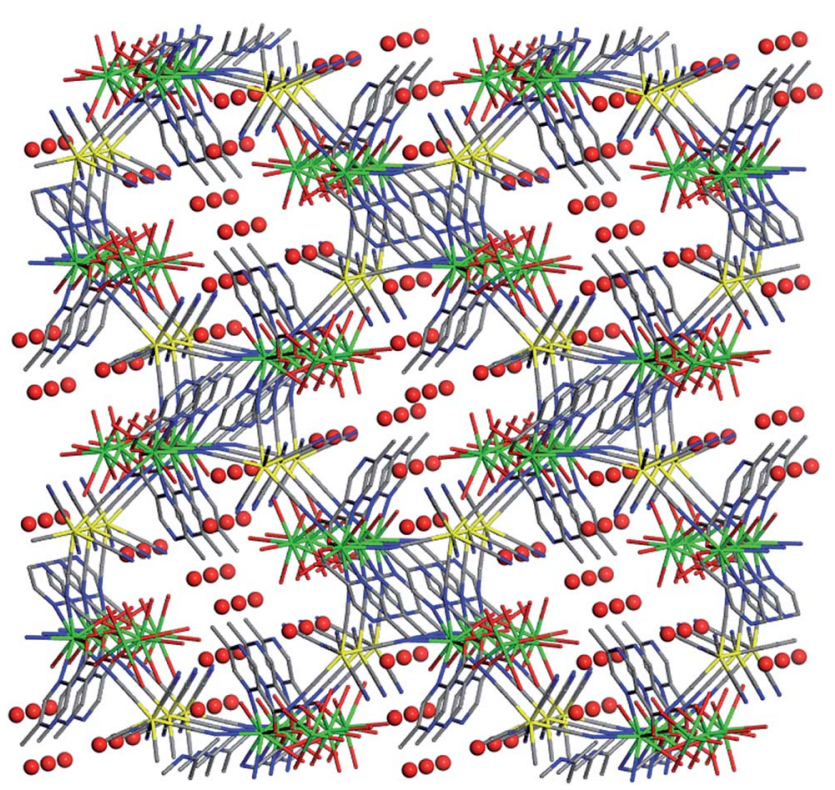

Fig. 1 Crystal structure of the NdMo-MOF viewed along the $b$-axis, showing the hydrophilic channels (the red spheres denote the oxygen atoms of the lattice water molecules). 
Furthermore, $\mathrm{CO}_{2}$ adsorption studies show that this framework is very flexible. ${ }^{\mathbf{4}}$ Based on these studies, we hypothesised that the rich water content of this MOF, both as lattice and coordinated water molecules, would make it ideal for studying proton conductivity. To test this hypothesis, we had to determine the framework stability after the removal of these water molecules. Fig. 2 shows the thermogravimetric analysis (TGA) and differential scanning calorimetry (DSC) curves for the pristine (i.e., as synthesised) NdMo-MOF. The first weight loss occurs at $80{ }^{\circ} \mathrm{C}$, corresponding to the removal of lattice water. $^{20,34}$ The endothermic DSC effect associated with this weight loss indicates that no structural changes occur within the framework. This observation is also supported by the IR and PXRD studies on the sample activated at $80^{\circ} \mathrm{C}$ (see Fig. $\mathrm{S} 1$ in the ESI $\dagger$ ). The second weight loss corresponds to the removal of coordinated water molecules and it is also accompanied by a small endothermic shoulder (Fig. 2). The major weight loss, which occurs above $300{ }^{\circ} \mathrm{C}$, is caused by the framework collapse and decomposition.

To study the effect of both coordinated and lattice water on the proton conductivity, we then used samples that were activated at three temperatures: $80{ }^{\circ} \mathrm{C}, 130{ }^{\circ} \mathrm{C}$ and $150{ }^{\circ} \mathrm{C}$. In this way, we could assess the effects of the removal of different water "types". The proton conductivity was measured using EIS analysis. Time-dependent control experiments showed that the samples reach equilibrium after $2 \mathrm{~h}$ (see Fig. S2 in the ESI $\dagger$ ), and all impedance data were then measured at equilibrium. The resistance values were calculated from the semicircles of the socalled Nyquist plots (Fig. S3†). ${ }^{\mathbf{4 4 , 4 5}}$ From these, one can calculate the proton conductivity values using eqn (1), where $L$ is the sample thickness, $A$ is the sample surface area and $S$ is the resistance.

$$
\delta=L /(S \times A)
$$

The Nyquist plot displays a partial semicircle at high frequencies and a tail at lower frequencies which arise from distinct grain interior and grain boundary contributions (see Fig. S3 $\dagger$ ). The grain interior conductivity is calculated from the

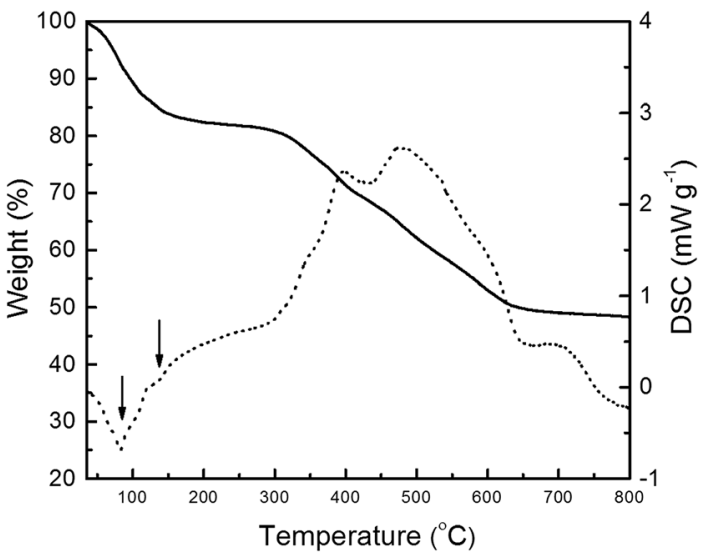

Fig. 2 TGA (continuous line) and DSC (dotted line) analyses of the assynthesised NdMo-MOF. The arrows indicate the loss of lattice and coordinated water, respectively. higher frequencies contributions. According to the standard Nyquist plots, we can calculate the permittivity based on the proton conductivity double-layer capacity. The permittivity is 55 , which is in the range of the water permittivity. ${ }^{46-48}$ To further confirm the conductivity of the as-synthesised NdMo-MOF, we also ran the DC conductivity measurements. From the results of both DC and EIS measurements, the conductivities are at the same order of magnitude $\left(10^{-7} \mathrm{~S} \mathrm{~cm}^{-1}\right)$ (see Fig. S3†).

Then, to investigate how the specific presence of lattice water affects the proton conductivity, we ran an EIS analysis using a sample that was activated at $80{ }^{\circ} \mathrm{C}$ under varied degrees of relative humidity. The conductivity increased from $4.2 \times 10^{-9} \mathrm{~S}$ $\mathrm{cm}^{-1}$ to $2.8 \times 10^{-3} \mathrm{~S} \mathrm{~cm}^{-1}$ when the relative humidity increased from $0 \%$ to $98 \%$ (see Fig. 3). The latter value is comparable to the best proton-conducting MOFs whose proton conduction is solely mediated by water molecules, either lattice or coordinated (a detailed comparison is given in Table $\mathrm{S} 1$ in the ESI $\dagger) .{ }^{29,49}$ Moreover, the strong dependence of conductivity on humidity, with the conductivity steadily increasing at $98 \%$ indicates that the proton is the mobile ion. These results also show that the coordinated water is a poor proton conductor. This is because at zero (or low) relative humidity, the only path for proton conduction is the hydrogen bonding formed by the coordinated water molecules. Increasing the relative humidity facilitates the incorporation of lattice water molecules within the flexible MOF channels. This improves the proton conductivity significantly, indicating that the lattice water is critical for achieving high proton conductivity.

Subsequently, to understand the proton conduction mechanism mediated by the lattice water, we compared the impedance values at different temperatures, while keeping the relative humidity constant at $44 \%$. The impedance ranged from $1.4 \times$ $10^{-4}$ at $90{ }^{\circ} \mathrm{C}$ down to $1.7 \times 10^{-5} \mathrm{~S} \mathrm{~cm}^{-1}$ at $30{ }^{\circ} \mathrm{C}$ (Fig. 4, top). From these measurements we derived an Arrhenius activation energy of $0.39 \mathrm{eV}$, or $37 \mathrm{~kJ} \mathrm{~mol}^{-1}$ (Fig. 4, bottom). The relatively low $E_{\mathrm{a}}$ value suggests that the proton transfer in this MOF follows the Grotthuss mechanism. ${ }^{50}$ This mechanism involves hopping in which a proton hops from a proton donor to an

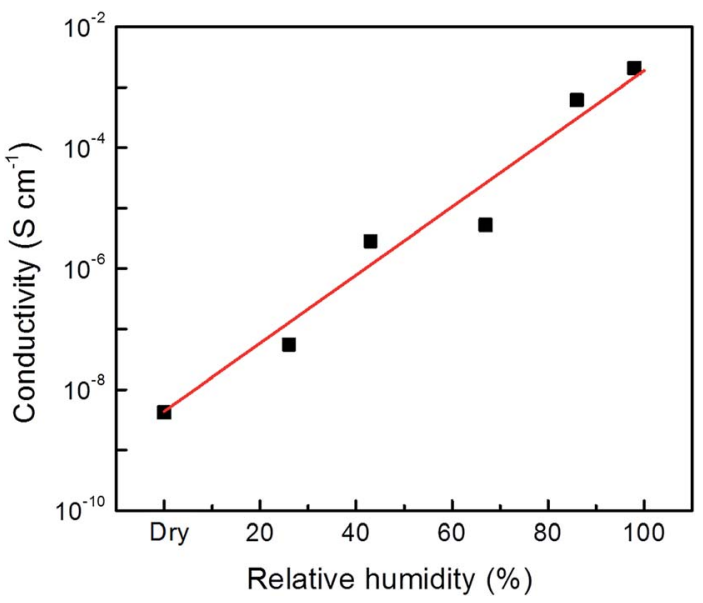

Fig. 3 The proton conductivity measured at $21^{\circ} \mathrm{C}$ and under different relative humidities (dry, 26\%,43\%,67\%, $86 \%$ and $98 \%$ ) for the NdMoMOF activated at $80^{\circ} \mathrm{C}$. 
acceptor along a hydrogen bond, and reorientation in which a hydrogen bond is cleaved and the proton reorients to another proton acceptor. ${ }^{51-53}$

To study the role of lattice water molecules on the proton conductivity and also confirm the structural flexibility of the framework, we ran impedance analyses using the pristine NdMo-MOF activated at $130{ }^{\circ} \mathrm{C}$ and $150{ }^{\circ} \mathrm{C}$, respectively (data shown in the ESI, Fig. S4 $\dagger$ ). The activation at these temperatures corresponds to the partial removal (at $130{ }^{\circ} \mathrm{C}$ ) or the complete removal (at $150{ }^{\circ} \mathrm{C}$ ) of the coordinated water. In the first case the MOF still retains its original framework and shows low proton conductivity (Fig. S4(a) $\dagger$ ). But when heated to $150{ }^{\circ} \mathrm{C}$, all the coordinated water is removed and the structure changes (see the FTIR spectra and PXRD patterns in Fig. S5-S7 in the ESI $\dagger$ ), and the dry MOF acts as the dielectric material of the capacitor in the impedance measurement (Fig. S4(b) $\dagger$ ). Subsequently, we re-checked the proton conductivity of the activated samples at $100 \%$ relative humidity. The samples activated at $80^{\circ} \mathrm{C}$ and 130 ${ }^{\circ} \mathrm{C}$ showed proton conductivities of $2.8 \times 10^{-3} \mathrm{~S} \mathrm{~cm}^{-1}$ and $2.1 \times$ $10^{-3} \mathrm{~S} \mathrm{~cm}^{-1}$, respectively. Interestingly, the sample that was activated at $150{ }^{\circ} \mathrm{C}$ had a slightly higher proton conductivity (9.0 $\times 10^{-3} \mathrm{~S} \mathrm{~cm}^{-1}$, see Fig. S8 $\dagger$ ). This high value corresponds to the ionic conduction arising from free $\left[\mathrm{Mo}(\mathrm{CN})_{8}\right]^{4-}$ and likely $\mathrm{Nd}^{3+}$
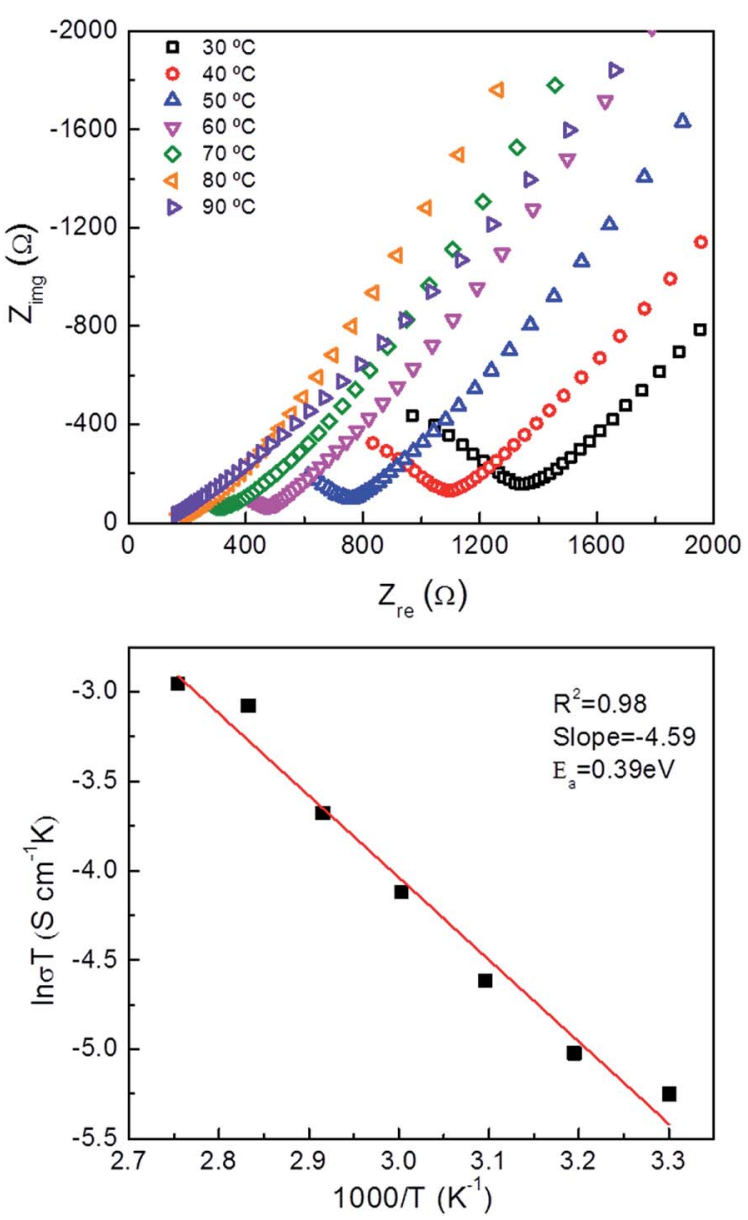

Fig. 4 Nyquist plots measured at $44 \%$ relative humidity and different temperatures (top) and the corresponding Arrhenius plot (bottom) for the NdMo-MOF activated at $80^{\circ} \mathrm{C}$. ions formed by the partial decomposition of the NdMo-MOF activated at $150{ }^{\circ} \mathrm{C}$. Indeed, a light yellow colour of the solution is observed by immersing the activated NdMo-MOF in water (see Fig. S8b $\dagger$ ). This colour is typical of free $\left[\mathrm{Mo}(\mathrm{CN})_{8}\right]^{4-}$ ions in water. Note, however, that this decomposition process is minor and most of the activated MOF returns to its original structure upon hydration. The fact that the proton conductivities of the samples activated at $80{ }^{\circ} \mathrm{C}$ and $130{ }^{\circ} \mathrm{C}$ are similar suggests that both return to their original structure upon water exposure (see Fig. S9 and S10 in ESI $\dagger$ ). These results affirm the robustness of the NdMo-MOF, a key feature for potential applications as a proton-conducting material. Furthermore, they also confirm that the hydrogen-bonding network established by both coordinated and lattice water molecules are responsible for the proton transport. In the case of the sample activated at $150{ }^{\circ} \mathrm{C}$, the transformation to a new framework may account for the higher conductivity.

To understand the structural changes that occur upon activation at different temperatures as well as the reversible changes when exposed at different relative humidities, we performed additional IR, TGA and PXRD characterization (see Fig. S4-S6 in ESI $\dagger$ ). The IR spectrum of the pristine MOF shows a broad strong peak at $2100 \mathrm{~cm}^{-1}$ corresponding to $\nu_{\mathrm{CN}}$ of both
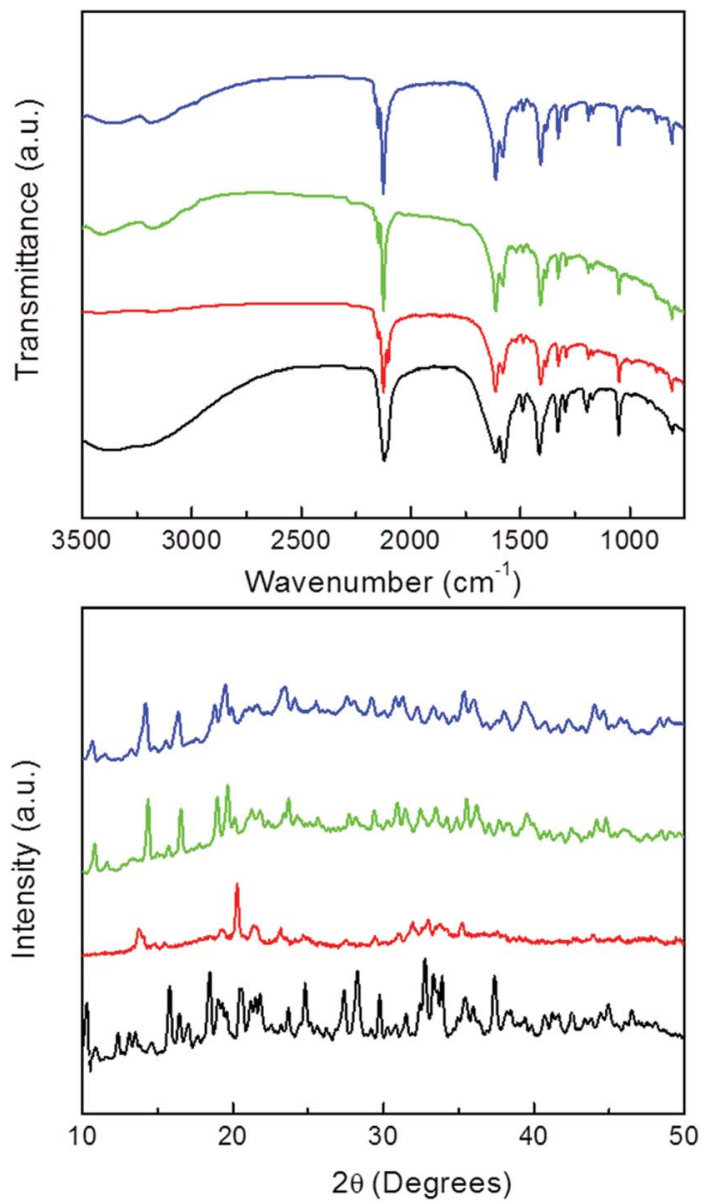

Fig. 5 IR (top) and PXRD (bottom) for the as-synthesised NdMo-MOF (black), the sample activated at $150{ }^{\circ} \mathrm{C}$ (red), immersed in water for 1 week (green) and after the proton conductivity measurement (blue). 
terminal and bridge cyanide groups (see Fig. $\mathrm{S} 5 \dagger$ ). The broad peak between $3200-3500 \mathrm{~cm}^{-1}$ is due to the $\nu_{\mathrm{O}-\mathrm{H}}$ from both coordinated and lattice water molecules. Note that this peak reduces in intensity for the sample activated at $80{ }^{\circ} \mathrm{C}$ and $130{ }^{\circ} \mathrm{C}$, and disappears completely for the sample activated at $150{ }^{\circ} \mathrm{C}$. Examining the MOF sample that was activated at $80^{\circ} \mathrm{C}$ shows that its structure remains the same as the original MOF (see Fig. 4 and 5). It is clear from both the IR and the TGA analysis that the sample activated at $130{ }^{\circ} \mathrm{C}$ still contains some coordinated water while the MOF activated at $150{ }^{\circ} \mathrm{C}$ does not contain any more water (see Fig. S5 and S7 $\dagger$ ). Similarly, the powder diffraction patterns also suggest that the MOF structure does not change when activated at $80{ }^{\circ} \mathrm{C}$ or at $130^{\circ} \mathrm{C}$ (Fig. S6†). Conversely, there are significant changes in the PXRD of the MOF activated at $150{ }^{\circ} \mathrm{C}$. Once the six water molecules coordinated to one of the $\mathrm{Ln}^{3+}$ ions are removed, this ion must fill its coordination geometry with other donors. The most accessible donors are neighboring cyanide and carboxylate groups, resulting in new $\mathrm{Ln}-\mathrm{O}$ and $\mathrm{Ln}-\mathrm{N}$ bonds and a totally different structure. To prove the hypothesis of this structural transformation, the MOF activated at $150{ }^{\circ} \mathrm{C}$ was immersed in water. Then, using IR and PXRD, we traced the structural changes for the samples after the water uptake as well as after proton conductivity measurements. Indeed, both samples are converted to a new but similar structural topology after immersing in water for enough time, as well as after proton conduction (Fig. 5). The broad water peak from the IR indicates the regaining of water. The PXRD confirms the crystalline structure but the formation of a new structure. Additional confirmation came from TGA analysis (Fig. S11 †).

To get further insight in the structural transformation of the NdMo-MOF activated at $150{ }^{\circ} \mathrm{C}$, we studied its water affinity by water adsorption (Fig. 6). We found that this activated MOF shows a water uptake of $c a .100 \mathrm{~cm}^{3} \mathrm{~g}^{-1}$ at STP, corresponding to $c a .4 .5 \mathrm{mmol}$ per formula unit. This agrees with the TGA analysis (see Fig. S12†) which shows that the water removal occurs at $c a .150{ }^{\circ} \mathrm{C}$. These results also show that the thermal stability of the new framework is similar to the original one,

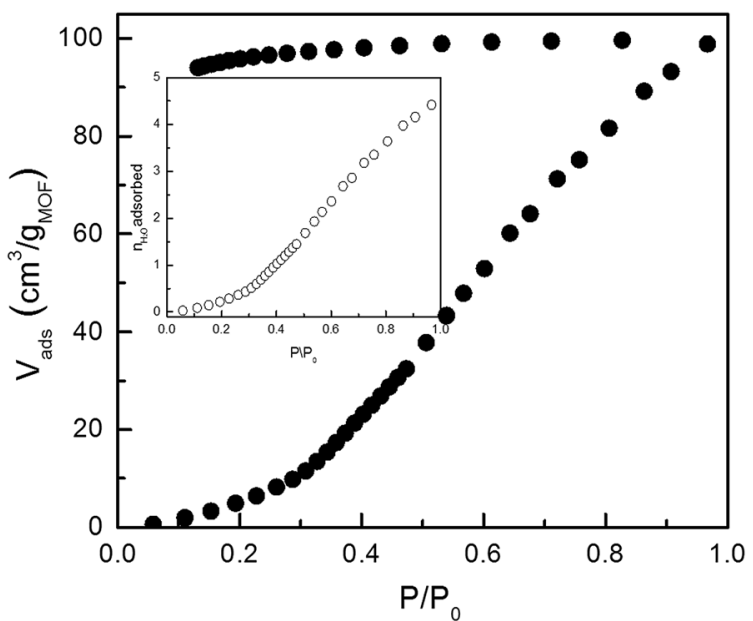

Fig. 6 Water adsorption isotherm of the as-synthesised NdMo-MOF activated at $150{ }^{\circ} \mathrm{C}$. confirming that that the carboxylate and cyanide-bridges within the framework are preserved ( $c f$. the IR and PXRD studies shown in Fig. S5-S7 in ESI†). The same studies also show that this water is difficult to desorb. The water molecules bind strongly to the framework, most likely as coordinated water. Importantly, all these results show that the NdMo-MOF activated at $150{ }^{\circ} \mathrm{C}$ transforms to the same structural phase when exposed to $100 \%$ relative humidity and after water adsorption measurements.

\section{Conclusions}

The framework of the NdMo-MOF $\left[\mathrm{Nd}(\mathrm{mpca})_{2} \mathrm{Nd}\left(\mathrm{H}_{2} \mathrm{O}\right)_{6^{-}}\right.$ $\left.\mathrm{Mo}(\mathrm{CN})_{8}\right] \cdot 6 \mathrm{H}_{2} \mathrm{O}$ features octagonal hydrophilic channels that make it one of the best proton-conducting MOFs. These channels contain two "types" of water molecules: coordinated ('inthe-framework') water and lattice (absorbed) water. Our studies show that it is the lattice water which are responsible for the proton conductivity. The lattice water molecules form a hydrogen-bonding network, through which protons "hop" along via the Grotthuss mechanism. The fact that (unlike most MOFs) this material is also stable both in water and at relatively high temperatures (up to $150{ }^{\circ} \mathrm{C}$ ) makes it a promising candidate for real-life applications. As we showed earlier, this class of materials has also special luminescence and magnetic properties. ${ }^{41,42}$ Combining these with ionic conductivity opens opportunities for designing proton-conducting switches controlled by temperature, light and/or external magnetic fields. ${ }^{40}$

\section{Acknowledgements}

YG thanks the China Scholarship Council for a PhD fellowship. This work is part of the Research Priority Area Sustainable Chemistry of the University of Amsterdam, http:// www.suschem.uva.nl.

\section{References}

1 Z. Strassberger, S. Tanase and G. Rothenberg, RSC Adv., 2014, 4, 25310-25318.

2 E. V. Ramos-Fernandez, N. R. Shiju and G. Rothenberg, RSC Adv., 2014, 4, 16456-16463.

3 V. R. Calderone, N. R. Shiju, D. Curulla-Ferré, S. Chambrey, A. Khodakov, A. Rose, J. Thiessen, A. Jess and G. Rothenberg, Angew. Chem., Int. Ed., 2013, 52, 4397-4401.

4 F. Barbir, PEM fuel cells: theory and practice, Academic Press, 2012.

5 M. Casciola, G. Alberti, M. Sganappa and R. Narducci, J. Power Sources, 2006, 162, 141-145.

6 S. Lee, S. Mukerjee, J. McBreen, Y. Rho, Y. Kho and T. Lee, Electrochim. Acta, 1998, 43, 3693.

7 S. J. Zaidi, S. Mikhailenko, G. Robertson, M. Guiver and S. Kaliaguine, J. Membr. Sci., 2000, 173, 17.

8 J. Fang, X. Guo, S. Harada, T. Watari, K. Tanaka, H. Kita and K.-I. Okamoto, Macromolecules, 2002, 35, 9022.

9 H. Wang, B. A. Holmberg, L. Huang, Z. Wang, A. Mitra, J. M. Norbeck and Y. Yan, J. Mater. Chem., 2002, 12, 834. 
10 G. Alberti, M. Casciola, D. Capitani, A. Donnadio, R. Narducci, M. Pica and M. Sganappa, Electrochim. Acta, 2007, 52, 8125.

11 A. Morozan and F. Jaouen, Energy Environ. Sci., 2012, 5, 9269.

12 S. Horike, D. Umeyama and S. Kitagawa, Acc. Chem. Res., 2013, 46, 2376.

13 Y. Ren, G. H. Chia and Z. Gao, Nano Today, 2013, 8, 577.

14 T. Yamada, K. Otsubo, R. Makiura and H. Kitagawa, Chem. Soc. Rev., 2013, 42, 6655.

15 S. Chandra, T. Kundu, S. Kandambeth, R. BabaRao, Y. Marathe, S. M. Kunjir and R. Banerjee, J. Am. Chem. Soc., 2014, 136, 6570.

16 P. Ramaswamy, N. E. Wong and G. K. Shimizu, Chem. Soc. Rev., 2014, 43, 5913.

17 X. Zhao, C. Mao, X. Bu and P. Feng, Chem. Mater., 2014, 26, 2492.

18 B. Gil-Hernández, S. Savvin, G. Makhloufi, P. Núñez, C. Janiak and J. Sanchiz, Inorg. Chem., 2015, 54, 1597.

19 T. Higuchi, T. Owaku, Y. Iida, E. Sakai, M. Kobayashi and H. Kumigashira, Solid State Ionics, 2015, 270, 1.

20 D. Ma, Y. Li and Z. Li, Chem. Commun., 2011, 47, 7377.

21 T. Kundu, S. C. Sahoo and R. Banerjee, Chem. Commun., 2012, 48, 4998.

22 S. Sen, N. N. Nair, T. Yamada, H. Kitagawa and P. K. Bharadwaj, J. Am. Chem. Soc., 2012, 134, 19432.

23 M. Yoon, K. Suh, S. Natarajan and K. Kim, Angew. Chem., Int. Ed., 2013, 52, 2688.

24 W. J. Phang, H. Jo, W. R. Lee, J. H. Song, K. Yoo, B. Kim and C. S. Hong, Angew. Chem., Int. Ed., 2015, 54, 5142.

25 Q. G. Zhai, C. Mao, X. Zhao, Q. Lin, F. Bu, X. Chen, X. Bu and P. Feng, Angew. Chem., Int. Ed., 2015, 54, 7886.

26 P. van Rijn, M. Tutus, C. Kathrein, L. Zhu, M. Wessling, U. Schwaneberg and A. Böker, Chem. Soc. Rev., 2013, 42, 6578.

27 M. Yoon, K. Suh, S. Natarajan and K. Kim, Angew. Chem., Int. Ed., 2013, 52, 2688.

28 S. Horike, D. Umeyama, M. Inukai, T. Itakura and S. Kitagawa, J. Am. Chem. Soc., 2012, 134, 7612.

29 (a) R. M. Colodrero, P. Olivera-Pastor, E. R. Losilla, D. Hernández-Alonso, M. A. Aranda, L. Leon-Reina, J. Rius, K. D. Demadis, B. Moreau and D. Villemin, Inorg. Chem., 2012, 51, 7689; (b) X. Y. Dong, R. Wang, J. Z. Wang, S. Q. Zang and T. C. W. Mak, J. Mater. Chem. A, 2015, 3, 641.

30 R. M. Colodrero, K. E. Papathanasiou, N. Stavgianoudaki, P. Olivera-Pastor, E. R. Losilla, M. A. Aranda, L. LeónReina, J. S. Sanz, I. Sobrados and D. Choquesillo-Lazarte, Chem. Mater., 2012, 24, 3780.
31 F. Costantino, A. Donnadio and M. Casciola, Inorg. Chem., 2012, 51, 6992.

32 J. M. Taylor, K. W. Dawson and G. K. Shimizu, J. Am. Chem. Soc., 2013, 135, 1193.

33 P. Ramaswamy, R. Matsuda, W. Kosaka, G. Akiyama, H. J. Jeon and S. Kitagawa, Chem. Commun., 2014, 50, 1144.

34 T. Wu, L. Shen, M. Luebbers, C. Hu, Q. Chen, Z. Ni and R. I. Masel, Chem. Commun., 2010, 46, 6120.

35 A. Mallick, T. Kundu and R. Banerjee, Chem. Commun., 2012, 48, 8829.

36 P. C. Rieke and N. E. vanderborgh, J. Membr. Sci., 1987, 32, 313.

37 S. C. Sahoo, T. Kundu and R. Banerjee, J. Am. Chem. Soc., 2011, 133, 17950.

38 A. Mallick, T. Kundu and R. Banerjee, Chem. Commun., 2012, 48, 8829.

39 S. S. Nagarkar, S. M. Unni, A. Sharma, S. Kurungot and S. K. Ghosh, Angew. Chem., Int. Ed., 2014, 53, 2638.

40 M. Ferbinteanu, F. Cimpoesu and S. Tanase, Metal-Organic Frameworks with $d-f$ Cyanide Bridges: Structural Diversity, Bonding Regime, and Magnetism, Springer, 2014, pp. 185-229.

41 S. Tanase, F. Prins, J. M. M. Smits and R. de Gelder, CrystEngComm, 2006, 8, 863.

42 S. Tanase, M. C. Mittelmeijer-Hazeleger, G. Rothenberg, C. Mathonière, V. Jubera, J. M. M. Smits and R. de Gelder, J. Mater. Chem., 2011, 21, 15544.

43 R. Plessius, R. Kromhout, A. L. Dantas Ramos, M. Ferbinteanu, M. C. Mittelmeijer-Hazeleger, R. Krishna, G. Rothenberg and S. Tanase, Chem.-Eur. J., 2014, 20, 7922. 44 G. W. Walter, Corros. Sci., 1986, 26, 681.

45 A. Shigematsu, T. Yamada and H. Kitagawa, J. Am. Chem. Soc., 2011, 133, 2034-2036.

46 N. C. Jeong, B. Samanta, C. Y. Lee, O. K. Farha and J. T. Hupp, J. Am. Chem. Soc., 2011, 134, 51.

47 J. Stankiewicz, M. Tomás, I. T. Dobrinovitch, E. ForcénVázquez and L. R. Falvello, Chem. Mater., 2014, 26, 5282.

48 X.-Y. Dong, R. Wang, J.-B. Li, S.-Q. Zang, H.-W. Hou and T. C. Mak, Chem. Commun., 2013, 49, 10590-10592.

49 Q. Tang, Y. Liu, S. Liu, D. He, J. Miao, X. Wang, G. Yang, Z. Shi and Z. Zheng, J. Am. Chem. Soc., 2014, 136, 12444.

50 C. J. T. de Grotthuss, Ann. Chim., 1806, 58, 54-73.

51 H. R. Allcock, M. V. Phelps, E. W. Barrett, M. V. Pishko and W.-G. Koh, Chem. Mater., 2006, 18, 609.

52 D. Marx, A. Chandra and M. E. Tuckerman, Chem. Rev., 2010, 110, 2174.

53 T. Ogawa, T. Aonuma, T. Tamaki, H. Ohashi, H. Ushiyama, K. Yamashita and T. Yamaguchi, Chem. Sci., 2014, 5, 4878. 